\title{
Making a Mark-Time Changing Politics from Estonia: An Alternative Idea for the British, Bulgarian and Estonian EU Presidency
}

\author{
Dirk-Hinnerk Fischer \\ Tallinn University of Technology \\ Akadeemia tee 3 , \\ Tallinn 12618, Estonia \\ E-mail: Dirk-Hinnerk.Fischer@ttu.ee
}

\begin{abstract}
Estonia is famous among politicians for its e-Governance policies. One core ingredient for this progress is the abolishment of outdated technologies and standards as this kind of legacy policy slows down the innovation process. This short paper adapts the Estonian approach towards legacy policy and proposes a political symbol initiated by the EU Presidency Trio of the United Kingdom, Bulgaria and Estonia. The entire topic was inspired by the motivation of the Estonian government to use the presidency to make a mark for Estonia. The twice-yearly occurring process of introducing and disabling the summertime, is not only annoying but has also almost exclusively negative impacts. Meanwhile, the summertime itself comes with many aspects of questionable impact and even opposing empirical results, but it also has some generally agreed upon positive influences. This paper takes side against the process of changing times, but does not take position for one of the possible solutions. This short article shall only inform and show the possibilities in regard to the summer time, the EU presidency and the political symbolism of celebrating the centenary of the First World War.
\end{abstract}

Keywords: Council of the EU, daylight saving time, integration policy, summertime, Trio Presidency 


\section{Introduction}

The observation of an unnecessary and overcome policy and the political willingness to put Estonia on the international map are the two issues driving this paper, but these issues are also driving the Estonian politics. Thus the paper does not approach one of the big issues of our time but rather a custom to which we have all become so used to that we do not even question its purpose any more.

One question could elaborate the objective of this research: Who, in a modern world, benefits from the changing of the clocks?

The twice-yearly repetition of changing clocks is still in place in about 70 countries in the world. Many countries such as China, Russia, Argentina or India, and thus the governments of the majority of people on earth, have distanced themselves from this policy. In other big countries like Australia, Brazil, the U.S. or Canada, there are no regulations implementing the law on national level rather than some states change the time and others do not.

The Member States of the European Union are the biggest number of conclusively organized countries who have adopted the summertime. In general, the summertime is a Western tradition that has already surpassed its peak of influence. Most of the rest of the world is not changing to summertime.

The first step in this paper is to take a look at the historical background of the process. The second step is to go into greater detail on the international discussion regarding the summertime. The third step will be to investigate the pros and cons of the process for companies, private persons and governments.

As this paper is written from an Estonian perspective, a brief summary of the abolishment of the summertime that failed in Estonia before the country joined the European Union is due. It is also necessary to mention the differences between the attempt back then and the proposed jurisdiction. Many things have changed since then and Estonia is not only going to be the EU Council's President in early 2018, but is becoming more and more known worldwide as one of the decisive players for e-Governance issues. Both of these things, the Council presidency and e-Governance, are elite projects which in many countries do not really penetrate the masses. The Trio has been shown to be a good method to improve the continuance of the political process (Raik, 2015), but to achieve this continuance, a tri-state cooperation needs a determined program and objective for their cumulated terms of presidency. The proposed political debate would help all three states to make a mark on the map of the average European citizen, 
which would especially be important for Bulgaria and Estonia, as the UK should already be well known to most European citizens.

The purpose of the paper is to offer an additional alternative to how Estonia and its Government might use the EU presidency to establish themselves as more than capable innovators and administrators.

Some might say that with all the IT we got nowadays we should not bother with such structural things that are widely solved by software. The argument against this is easy and clear as legacy policy is no longer of interest to our society and, secondly, every report on business problems related to the changing of the clocks are evidence enough to abolish the process of changing time.

The time zones are also going to be analyzed, since some progressive thinkers are already questioning their efficiency and the issue needs to be mentioned in an analysis of the modern time system.

This paper will argue in favour of an international coordination mechanism instead of a radical change within the system.

It is important to mention that in neither topic an asynchronous solution could and should be an option as European countries are too intertwined to disagree on such an important issue. Estonia already tried to take a time changing step alone once and had to learn from that experience. The objective should thus be a synchronous abolishment or year-round introduction of the summertime. The entire action might and could be marketed as a political symbol for a more peaceful, interconnected and opened "new" Europe and European Union, especially in times of growing extremism and political pressure.

\section{Historical development}

The concept of a summertime is not one of the last century, but it was first introduced and used in the early 20th century. The main argument in those days and until today has been to save energy. Reportedly, the Ben Franklin was the first who articulated the idea as businesses would save a lot of money for candles if the opening hours would be more coinciding with the daylight (Kotchen \& Grant, 2008).

The summertime was first introduced into common law in the early 20th century by Germany during the First World War. The German Reich under Wilhelm 
II introduced it on the 1st of May 1916. The policy was adopted by most participating countries during the war. Afterwards some countries kept it in use while others abolished it (Reincke \& van den Broek, 1999). The U.S., for example, introduced it in 1917 and repealed it again in August 1919 (Kamstra, Kramer \& Levi, 2000).

Throughout the century, countries changed the implementation with quite impressive flexibility. Only a few countries show consistency in the usage of the summertime. Summarizing the main patterns shows that the summertime was introduced during periods of crisis, such as the Second World War or the oil crisis. Presumably because the myth of saving energy with the help of the changing time was kept alive for a long time. Some countries, like the United Kingdom, even experimented with double summertime and year-round summertime. However, from March 1968 to October 1971, a trial was concluded with the notion that it would be impossible to quantify results and thus no position for or against was taken (Aries \& Newsham, 2008).

In 1980, the European Council began harmonizing the process among its Member States as the periods of introduction and even the usage itself have been highly diversified before that (Reincke \& van den Broek, 1999). This synchronization process continued and, in 2000, the European Council passed a directive to implement unified summertime arrangements, with additional later applications to new Member States (EC, 2001).

Estonia attempted to abolish the summertime more than ten years ago and was not successful as the public opinion turned quickly against the new law. The main reasons for the paradigm shift were that the international communication and trade suffered, and also a shorter sunny evening in the summer was not seen as favourable. Scientifically interesting is that the energy savings were and have not been worth mentioning (Gunter, 2002). The change also happened under the Reform Party's leadership, which is in power in 2015 and still will be in 2018 at the time of Estonia's Council presidency.

It is also worth mentioning that in 2000 also Latvia changed to not using the summertime any more, but only a year later they reintroduced it as a way of bringing more sunlight to the Latvians (BNS, 2001). Modern Bulgaria introduced the summertime in 1997 and adapted it to the European norms (ICF, 2014; FOCUS, 2015).

Thus, out of the trio, the British and the Estonian government have past experiences and data on the public reaction among their people, but the times have changed and a single-handed abolishment is off the table. So now these 
governments are able to implement change in Europe on an international scale. But for a successful introduction of this process the three countries will be needing international partners. The opinions present in other European regions will be briefly summarized in the next subsection.

\section{International discussion}

In general, and in almost all European countries, the summertime is a topic that has not eluded criticism. This mixture of results can also be found in the research, as very controversial findings have been published over the last decades.

The first and oldest argument for the summertime was that of energy saving. In past times this was most probably true but there is no conclusive proof for it in modern times. Changed living and housing habits, air-conditioning and the mass usage of information and communication technologies (ICT) have eliminated or might even have reversed the energy saving effects (Aries \& Newsham, 2008). There is no conclusive proof for any savings at all. This accounts especially if the over-proportional economic and growth of population are taken into account. These tendencies come along with drastically changed living standards and consumption habits in most European regions over the last one hundred years (Fischer, 2015).

Kamstra, Kramer and Levi (2000) have shown that the summertime can even have a negative influence on the stock exchanges and that it implies averaged losses year by year. Finance is not the only sector impacted in a negative way. The agricultural sector is also subject to different negative impacts, among these, for example, the disturbed biological rhythm of farm animals like cows and a darker working day for farmers (Reincke \& van den Broek, 1999).

The discussion about the purpose of the changing process is not only a European one. For example, not all states of the U.S. actually have the summertime, or daylight saving time as they call it. A commission in California found in 2001 that at most 0.5 per cent of energy might be saved if anything at all. (Kandel \& Metz, 2001)

A more recent experimental study (Kotchen \& Grant, 2008) finds that the policy actually results in an increase in residential electricity demand of about 1 per cent. The most impacting factor here is the increase in consumption after the fall transition. The difference occurs due to the increase in heating and air conditioning. (Kotchen \& Grant, 2008) This experimental study was conducted 
in Indiana, U.S.A., and as such conducted at a comparable latitude to Spain, Italy or Greece.

Other studies carried out in the U.S., such as a study under Governor Arnold Schwarzenegger from the California Energy Commission in 2007, shows inconclusive energy saving results (Kandel \& Sheridan, 2007).

On the European level, an extensive study has been conducted for the Commission on the efficiency of the summertime (ICF, 2014). The study found very little proof to an impact on energy, as the technological and organizational advances made in the last decades have eliminated this effect. (ICF, 2014) The former possible ways to save energy have been annihilated by many aspects, one of which is most certainly the increased usage of air-conditioning (Kotchen $\&$ Grant, 2008). It can thus be concluded that the energy saving argument is no longer justified. Maybe it has been valid in the past, but modern living conditions and habits are different than those a hundred years ago.

The impact of the summertime on leisure and tourism is reportedly a positive one, which is not against all odds as the summer evenings are getting longer with the summertime (ICF, 2014). Even though modern working structures and more flexible organizations are limiting this impact to a certain extent, it still remains a fact that has to be considered.

Researchers from Chile have found that the changes in official times have an impact on the carbon oxide concentration in cities, which lowers the average quality of the air, but there is no long-term influence due to the second changing of time in fall. (Muñoz \& Schmitz, 2007)

Health problems have been reported in Germany and also the number of notification of sickness absences from work has been increased year by year by almost 15 per cent after the introduction of the summertime (DAK, 2015).

Another argument regarding an increased security due to more sunlight in the evening hours has found support in a not very recent study from 1995 showing that the daylight saving time actually saves lives within the U.S., as less pedestrians are hit by cars in the twilight (Ferguson et al., 1995). Another study from 1983 actually finds the opposite (Hicks, Lindseth \& Hawkins, 1983).

A more recent study found that workplace-related accidents increase after the switch. Meanwhile, the second part of the study using another database and shorter time periods does not find this correlation. (Barnes \& Wagner, 2009) 
The only conclusive finding seems to be that the number of accidents with deer after the spring change is shown to be exponentially increasing in comparison to normal accident rate (Haikonen \& Summala, 2001).

In the economic sphere, the real costs are very hard to estimate and nobody has actually done it so far, as the calculation is extremely complicated. The use of ICT is smoothing the process a lot for all of us, but still some transition costs remain. These costs are not only limited to the time lost adapting to the changing, but also occur within the ICT sector itself. (ICF, 2014) And despite all our technological improvements confusion remains among all kinds of entities and humans. For example, the Minister of Bavaria missed a call by German Chancellor Angela Merkel in 2014 due to the changing to the summertime (DPA, 2014). Humans stay humans and they may forget things. This missed call is most certainly not one of the reasons why the governing German Party of Angela Merkel (CDU or Christian-Democratic Union / Christlich Demokratische Union) decided to take a stand against the summertime in Europe. The CDU accepted the abolishment of the summertime as an official position in the program of the party (FAZ, 2014). A more important reason for this step might be that more than two-thirds of all Germans speak out against this twice-yearly repetition of the old and presumably unnecessary habit (forsa, 2015).

In France the situation is a little different as 27.4 per cent of people are indifferent and 38.8 per cent are against the current system of changing the clock. The interesting thing is that they even have an organization the objective of which is to lobby against the summertime (ACHdE, 2015).

Already since 1978, Switzerland has been in open opposition to the summertime as a public referendum rejected the policy, but due to complications in trade, tourism, finance and transport, the Parliament had to adapt the official time in Switzerland to the official time in its neighbouring countries. Switzerland, even though not a member of the EU, would thus be happy to join a world without the summertime (Schwander, 2013).

Russia, another neighbour of the EU, abolished the summertime in 2011 to limit the negative health impacts (ICF, 2014).

One of the most complete studies on the topic has been conducted in Turkey, where different scenarios of implementation have been discussed (Karasu, 2010). In the end, the government did not meet the suggestions, but the findings show once again the difficulty of measurement within this topic. It has also shown that, at the most, limited energy savings can be expected. (Karasu, 2010) 
The British government is running analyses every year and has found that the summertime on average saves around 80 lives and prevents 212 serious injuries each year. These studies also show that the process of turning the clocks back has a negative impact on these very positive statistics as the number of accidents increases significantly in autumn. (RoSPA, 2014)

The German government is currently running a study on the effects and results of the summertime. The results are expected late in the year 2015. This study will most probably determine the German position in the upcoming years. If this study finds in favour of the abolishment, Estonian politicians should seriously consider using their upcoming EU presidency for a greater good.

It is obvious that every European country, regardless its geographic position, cultural heritage and political system, has different perceptions about and connections to the summertime. It is thus challenging to find a unified approach, but a general critique of the current system is widely present. The difficulty within the project is that Europe is not a small country, but rather subject to very different climates and sunlight conditions. It is just rational that the opinions are different, as empirical findings are not conclusive either and there are only tendencies observable. In general the summertime seems to have some upsides but actually no real downside. On the other hand, the process of changing the time has almost exclusively negative effects on animals, humans and the society. Two ways of responding to this mixture of indicators are thinkable: introducing the summertime year round or returning to the standard time year round.

If we now think about a common market and a further European and worldwide integration, we have to see that the summertime is only one of the problems as the time zones also have their confusing impacts.

Some solutions have been proposed for this issue. One of the more creative approaches was introduced by Swatch, the Swiss watch manufacturing company which proposed a single time system called the Swatch Internet Time. This might be a solution for the future with a more integrated and ever more global or even space connected society. The system works with 1,000 beats that are not bound to time zones or other barriers but are always and everywhere the same. One beat consists of 86.4 seconds and is counted beginning from zero at midnight and ends with a thousand on the next midnight. Swatch also introduced a new Meridian through their headquarters in Switzerland. The idea behind this concept was that the Internet is universal and does not need time zones. (Lee \& Whitley, 2002; Lee \& Liebenau, 2000) 
Information can spread around the world within a blink of an eye. This new transportation velocity makes different time zones not only unnecessary but also confusing. Every one of us is used to having daylight at the middle of the counted time for every day, at least in Estonia for the longest part of the year. This habit will most probably stay like this during the upcoming decades and it is also not yet necessary to be changed, at least not on a large scale. The positive thing is that there is no need to eliminate the global solution in order to continue with the regional solutions.

The system proposed by Swatch might be considered slightly too complicated as it takes one unnecessary step and only adapts the already existing system of an absolute time system. The already existing system would be the Coordinated Universal Time (UTC). The UTC is a simpler system that is already used in nautical and aviation terms. The term UTC first appeared in the early 1960s and has been in use ever since. (Arias \& Guinot, 2004) In both of these really international trades, the UTC has proven itself to be an effective system. As the nautical system is already in use, why not emphasize the adaption of this proven addition? The system is simple as it only takes the Greenwich Time and uses it as a standard for the world. Everybody has seen it somewhere. It is present, but just not yet official.

In the context of the European Union, this time measurement could be introduced as an official time, so that meetings and schedules would not get mixed up by internationally travelling people. This time measurement is already in standard use for many people in international trade and most internationally working people are already aware of it, so why hesitate using it for official communication and introducing a double standard in public life.

A unified time would not matter too much to the public if it is introduced as a second official time, which means that it would co-exist with the local time. This co-existence would mean that the UTC can be used as a general standard for official matters.

Time zones themselves are a rather young concept, as they were introduced with the nautical standard time in the 1920s (Howse, 1980). The system is thus even younger than modern nations. And still both systems develop with an increase in the average travel intensity and travel speed. Neither nations nor time zones are a final concept in human history. Higher interaction led to bigger countries and faster travel made problems with unregulated time zones obvious. This process is very unlikely to stop in our current situation as average travel speed and international interaction are still very much developing. Both systems are 
continuously changed all over the world. Time changes have been mentioned, as Russia eliminated two time zones in 2011 and stopped changing the clocks while running on daylight saving time. In 2014, the Russian Duma again changed the time to the "original" winter time, as reportedly the doubled daylight saving time had caused a significant impact on public health (Stulov, 2014).

Also, many countries, even in Europe, struggle between separation and integration tendencies and issues. Countries including Turkey, Spain, UK or Ghana have been recently featured in the media in relation to these topics.

For thousands of years there has been no clock or time measurement at all. Time has been a construction of humanity and it is not a natural thing. But time has been always related to natural phenomena such as the orbiting of the sun. With that the local time changed from region to region depending on the point in time when the sun was at its highest position. One of the first mechanical timepieces was invented in 1657, which was way more accurate than water, sundial and other time counting mechanisms at that time. Before that, time could only be counted with a loss of accuracy of about 15 minutes per day. Within a few years, the new technologies enabled an accuracy loss of less than 10 seconds per day. The 1657 invention also led to the appearance of minutes and seconds on clocks. The consciousness of people for the existence of minutes and seconds emerged only afterwards. (Lee \& Liebenau, 2000) Technical development has thus changed the perception of time throughout history.

The concept of time zones was needed when global trade increased and the technological background had been developed, so that most travelling people were carrying a watch. Travel, trade, long-distance communication and general international communication increased and made the use of every particular local solar time obsolete. This can be exemplified by the U.S. in the 1870s when different railroads used multiple calculations and had thus different times for the same place. This system made travellers confront very practical problems, as the departure times differed significantly. Further problems, such as an increased number of train crashes through different time calculations, underlined the need for a new system. The system of time zones was introduced only in 1884 at the International Meridian Conference with a participation of 25 nations (Palmer, 2002).

The elimination of time zones would not be very practicable nowadays for those regions not close to the line of coinciding 12 o'clock and the highest point of the sun would be troubled as their sunlight time would shift from day to night and customs had to be changed, which is just not necessary and practicable. But to introduce an official communication time that would be used by all transport 
sectors would help to minimize the communicational errors and save time as well as be a political symbol not only for Europe but for the entire world for better communication and closer relations.

\section{An attempt to put Estonia on the map}

Estonian politics often focuses on the possibility to increase the international recognition of this small Baltic country. Putting Estonia on the map is not only the focus of the political or business elites, but also of the citizens. Nevertheless, most projects by the Estonian government and administration are elite projects, such as "paper free presidency". These projects are great technological steps and they set political marks, but the average person hears little about it, as it does not really impact their lives.

The EU presidency itself is a political and academic expert project and most people on the street do not even know which country currently holds the presidency or through which mechanisms it is distributed.

The point is that political Estonia will put itself in a highly favourable position if the administrative processes, soft and hard skills are well prepared for a smooth presidency, which is very likely as the administration is already working intensively on these preparations now. The first major official step in this direction has been successfully taken as Estonia will work with a Brussels-based presidency which is preferred by most partner countries as it smoothens the processes. Thus, Estonia will most probably not fail to leave a good impression on the European partners, but most of the general public will probably hear very little about the presidency. Nevertheless, the presidency gives an opportunity to make a mark, also one that sticks with the broad masses. This is a time in which a small group of countries can develop the European Union by initiating a beautiful political symbol.

This step can draw wide public attention to innovative projects, like the e-Residency, which is being developed in Estonia right now. It can also attract attention to earlier innovations, which have become routine in Estonia, but are still far in the future in most parts of Europe like e-ID, e-Voting and, especially, the e-Signature.

The recent political crisis has created a little more awareness about the existence of the country, but the international reports still mostly focus on security rather than attracting interest in the country. 
Estonian officials have to face a decision towards the approach of making a mark in Europe. Following a strict top-down interest creation approach is opposed to a more integrative multi-level approach. The current position of a top-down approach, by focusing on technological and administrative elites is a good start, but it does not really attract tourist attention.

Now Estonia can make a mark not only for a more peaceful future, but also against pointless or outdated bureaucracy. The elimination of legacy policy is a fundamental pillar of the technological development plan of the Estonian government. The political symbol proposed here would draw attention on a bigger scale. It would also stand for a peaceful long-term integration, also with our neighbouring countries.

One last point has to be mentioned and that is a topic that many technologically affine people are probably already thinking about. It is clear that modern technology is no longer challenged by the issue of changing to and from summertime, but some transaction costs have been briefly mentioned. Another negative aspect is that natural beings are impacted and challenged by the timechanging processes. The last aspect against the argument follows an Estonian way of argumentation and in the spirit of eliminating legacy policy-just because most programs no longer have a problem adapting does not mean that outdated standards should be kept.

\section{Summary and possible platforms}

In general, there are two ways to abolish summertime. Either Europe takes an easy step and returns to the "official" time or it adopts summertime as the new "official" year-round time. Within Europe, the latter is probably the preferred option as most people like to sleep in and would enjoy their evenings with an hour of longer sunlight, but it would move Europe's time zones one hour further to the west. Most probably, this procedure also would not harm the image of Europe in the world, but it might require some adaptation time internationally. An easier way would be a return to the "wintertime".

Even though a tendency toward summertime exists, the decision is one mostly based on feelings and not one based on facts, as the advantages of summertime over wintertime are already mostly and will probably be completely equalized by more flexible working conditions and a more efficient energy system. The important conclusion is that the process of changing clocks will be abolished. 
The second conclusion of this paper is that the EU should not hesitate to introduce an official double standard in time as an officially introduced UTC would help to smoothen the international processes in the entire EU.

This paper claims that the process of changing to summertime and the poor communication of international time are the two small issues that could be tackled within the Trio Presidency of Estonia, UK and Bulgaria. The proposed changes would simplify and improve international communication for the population, companies and governments. Implementing one of the two ideas into European law would already be a major step, while the changing process should enjoy higher priority as it has measureable effects on the wider population and it also attracts more public interest. The analysis made it obvious that an international approach is the only way that makes sense, as national solutions have triggered numerous problems in the past. The two discussed issues are not too important, yet significant enough to the entire European population so that these modifications could help to put Estonia on the map of the broad population.

The celebration of the passing of hundred years from the end of the First World War, dated to 18 October 2018, falls within the period of Bulgaria's presidency. So if a jurisdiction would be signed on that day it would be a signal not only within Europe, but internationally. For Estonia to share the glory with the traditionally EU-critical British and the emerging Bulgarians could make this symbol even more powerful. The success of such an attempt seems highly probable as important European and international political powers would be supporting the endeavour.

Much of the process obviously depends on the referendum in the UK. But for the purpose of this paper it is assumed that the economic, social and Scottish interests will prevail and that the UK will stay in the European Union.

David Cameron made visits to several European countries this year proclaiming a new, reformed and more adapted European Union. The symbolic reform proposed here should thus fit in the program of his government. It is a tiny step and its implementation could be organized without any greater impact on business or social life by the centenary of the end of the First World War.

Another result of a rejected exit-referendum would be that British politicians would also have an incentive to set a political symbol for a more adapted and less bureaucratic European future. The presidency is already too short to allow entrance to high politics, such "minor" issues would thus be a good way to make a mark and to further the European idea with less hurdles. 
From an Estonian viewpoint, sharing the glory of the idea would emphasize the purpose of the symbolic elimination of legacy policy on an international level, which would show other European governments how Estonia became so well developed in ICT and leave a lasting impression on international administrators.

To return to the question of who would benefit from the changing of the clocks, asked at the beginning of the paper: it is the people who are not involved in an accident due to the summertime and those enjoying longer summer evenings. The process of changing the clocks on the other hand benefits nobody. It disturbs and harms animals as well as humans. Impacts on the economy are not conclusive. In no area was there a conclusive positive finding for the changing process itself. Increased accidents and disturbed biorhythms are only two of the negative aspects. The differentiation between the process of changing and the different time systems should always be kept in mind, if such topic is being discussed. The summertime has its advantages, while the process of changing has not.

Thus, the essential point for this paper is that the Estonian government and its two partner countries should use the presidency to set a symbol for further development and a less bureaucratic future. A symbol 100 years after the end of the essential catastrophe of the 20th century. A symbol for a more peaceful and connected 21 st century, during which Europe learned from its past mistakes. A symbol easily set by introducing one official time and abolishing the processes of changing the clock, whether to the summertime around the year or to the standard time.

\section{Acknowledgments}

I would like to thank my supervisors Rainer Kattel from the Ragnar-Nurkse School of Governance and Innovation and Antonius Notermans from the Tallinn School of Economics and Business Administration of the Tallinn University of Technology. Furthermore would I like to thank Aksel Kirch and Tarmo Tuisk, also from the Tallinn University of Technology, for their help and advice. Lastly would I like to thank my brother, Claas, for his nautical advice on this paper.

Dirk-Hinnerk Fischer holds a master's degree in international economics and business administration from the University of Innsbruck, Austria. He is currently a PhD student at the Ragnar Nurkse School of Innovation and Governance of the Tallinn University of Technology. This is a supplementary article for the author as it slightly departs from his 
usual research. His dissertation articles focus on how to improve financial market regulation and on how to stabilize different structural layers of the financial markets by applying interdisciplinary research methods.

\section{References}

ACHdE (2015), Site D'information de l'Association Contre L'heure D'été Double, Pour La Réduction Des Avancements de L'heure Légale (France), Association Contre L'heure D'ete Double. Retrieved from http://heure-ete.net/argumentaire. htm [accessed Dec 2015]

Arias, E. F. \& Guinot, B. (2004), 'Coordinated Universal Time UTC: Historical Background and Perspectives,' Proceedings of the Journées Systèmes de Reférénce Spatio-Temporels, Observatoire de Paris, 20-22 September 2004, pp. 254-259.

Aries, M. B.C. \& Newsham, G. R. (2008), 'Effect of daylight saving time on lighting energy use: a literature review,' Energy Policy, vol. 36, no. 6, pp. 1858-1866. http://dx.doi.org/10.1016/j.enpol.2007.05.021

Barnes, C. M. \& Wagner, D. T. (2009), 'Changing to daylight saving time cuts into sleep and increase workplace injuries,' Journal of Applied Psychology, vol. 94, no. 5, pp. 1305-1317. http://dx.doi.org/10.1037/a0015320

BNS (2001), 'Latvia to switch back to summer time,' The Baltic Times. Retrieved from http://www.baltictimes.com/news/articles/4055/ [accessed Dec 2015]

DAK (2015), Umfrage Zur Zeitumstellung / DAK-Gesundheit. Website of the DAK. Retrieved from http://www.dak.de/dak/bundesweite_themen/Umfrage_zur_ Zeitumstellung-1588766.html [accessed Dec 2015]

DPA (2014), 'Wegen Zeitumstellung: Seehofer verschläft Merkel-Telefonat,' Handelsblatt, 4 April 2014. Retrieved from http://www.handelsblatt.com/ politik/deutschland/wegen-zeitumstellung-seehofer-verschlaeft-merkeltelefonat/9717140.html [accessed Dec 2015]

EC (2001), Directive 2000/84/EC of the European Parliament and of the Council of 19 January 2001 on summer-time arrangements, Official Journal of the European Union, L 031, 02.02.2001.

FAZ (2014), 'Parteitagsbeschluss: CDU will die Sommerzeit abschaffen,' Frankfurter Allgemeine Zeitung, 5 April 2014. Retrieved from http://www.faz.net/aktuell/politik/ inland/parteitagsbeschluss-cdu-will-die-sommerzeit-abschaffen-12882140.html [accessed Dec 2015]

Ferguson, S. A.; Preusser, D. F.; Lund, A. K.; Zador, P. L. \& Ulmer, R. G. (1995), 'Daylight saving time and motor vehicle crashes: the reduction in pedestrian and vehicle occupant fatalities,' American Journal of Public Health, vol. 85, no. 1, pp. 92-96. http://dx.doi.org/10.2105/AJPH.85.1.92 
Fischer, D.-H. (2015), 'A Comparison of the Economic Situation of Tyrol, Austria in Three Key Periods: 1908-1913, 1945-1950 and 2008-2013,' Baltic Journal of European Studies, vol. 5, no. 1, pp. 93-108. http://dx.doi.org/10.1515/bjes-2015-0007

FOCUS (2015), 'Bulgaria adopts daylight saving time,' Focus News Agency. Retrieved from http://focus-fen.net/news/2015/03/29/367810/bulgaria-adopts-daylightsaving-time.html [accessed Dec 2015]

forsa (2015), Meinungen Zur Zeitumstellung, Cologne: forsa Gesellschaft für Sozialforschung und statistische Analysen $\mathrm{mbH}$.

Gunter, A. (2002), 'Summer time returns to two Baltic states,' The Baltic Times, 4 April 2002. Retrieved from http://www.baltictimes.com/news/articles/6212/ [accessed Dec 2015]

Haikonen, H. \& Summala, H. (2001), 'Deer-vehicle crashes: extensive peak at 1 hour after sunset,' American Journal of Preventive Medicine, vol. 21, no. 3, pp. 209213. http://dx.doi.org/10.1016/S0749-3797(01)00352-X

Hicks, R. A.; Lindseth, K. \& Hawkins, J. (1983), 'Daylight saving-time changes increase traffic accidents,' Perceptual and Motor Skills, vol. 56, pp. 64-66. http:// dx.doi.org/10.2466/pms.1983.56.1.64

Howse, D. (1980), Greenwich Time and the Discovery of Longitude, 1st ed., Oxford \& New York: Oxford University Press.

ICF (2014), The Application of Summertime in Europe. A report to the European Commission Directorate-General for Mobility and Transport (DG Move), ICF International, 19 September 2014.

Kamstra, M. J.; Kramer, L. A. \& Levi, M. D. (2000), 'Losing sleep at the market: the daylight-savings anomaly,' American Economic Review, vol. 12, no. 3, pp. 10001005.

Kandel, A. \& Metz, D. (2001), Effects of Daylight Saving Time on California Electricity Use: California Energy Commission Staff Report, 23 May 2001.

Kandel, A. \& Sheridan, M. (2007), The Effect of Early Daylight Saving Time on California Electricity Consumption: A Statistical Analysis, California Energy Commission Staff Report, May 2007.

Karasu, S. (2010), 'The effect of daylight saving time options on electricity consumption of Turkey,' Energy, vol. 35, no. 9, pp. 3773-3782. http://dx.doi.org/10.1016/j. energy.2010.05.027

Kotchen, M. J. \& Grant, L. E. (2008), 'Does daylight saving time save energy? Evidence from a natural experiment in Indiana,' Review of Economics and Statistics, vol. 93, no. 4, pp. 1172-1185. http://dx.doi.org/10.1162/REST_a_00131

Lee, H. \& Liebenau, J. (2000), 'Time and the Internet at the turn of the millennium,' Time \& Society, vol. 9, no. 1, pp. 43-56. http://dx.doi.org/2000/03;9;1;43-56

Lee, H. \& Whitley, E. A. (2002), "Time and information technology: temporal impacts on individuals, organizations, and society," The Information Society, vol. 18, 
pp. 235-240. http://dx.doi.org/10.1080/01972240290075084

Muñoz, R. C. \& Schmitz, R. (2007), 'Morning peak of air pollutant concentrations in urban areas: Effect of time lag between emissions and turbulence,' 7th AMS Symposium on the Urban Environment, 10-13 September 2007, San Diego, California, USA.

Palmer, A. W. (2002), 'Negotiation and resistance in global networks: The 1884 International Meridian Conference,' Mass Communication and Society, vol. 5, no. 1, pp. 7-24. http://dx.doi.org/10.1207/S15327825MCS0501

Raik, E. (2015), “The 'Trio Presidency' of the Council of the European Union: Towards more continuity?" Baltic Journal of European Studies, vol. 5, no. 1, pp. 19-35. http://dx.doi.org/10.1515/bjes-2015-0003

Reincke, K.-J. \& van den Broek, F. (1999), Summer Time: Thorough Examination of the Implications of Summer-Time Arrangements in the Member States of the European Union, Executive Summary. Leiden: Research voor Beleid International.

RoSPA (2014), British Summertime Fact Sheet, The Royal Society for the Prevention of Accidents.

Schwander, P. (2013), 'Farbe Bekennen - Energie Sparen,' in S. Hirsbrunner, M. Buchs \& M. Zünd (eds.), Energieetikette, 2nd ed., Bern: Bundesamt für Energie - Swiss Federal Office of Energy.

Stulov, M. (2014), 'Russia to switch to permanent winter time,' The Moscow Times, 1 July 2014. Retrieved from http://www.themoscowtimes.com/news/article/russiato-switch-to-permanent-winter-time/502808.html [accessed Dec 2015] 